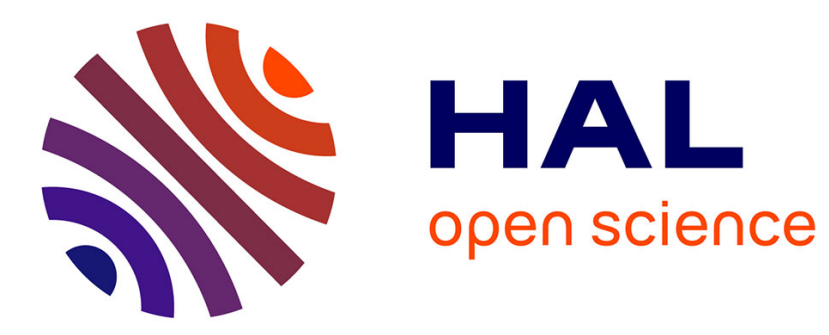

\title{
It is not only the cat that did it: How to prevent and treat congenital toxoplasmosis.
}

Florence Robert-Gangneux

\section{To cite this version:}

Florence Robert-Gangneux. It is not only the cat that did it: How to prevent and treat congenital toxoplasmosis.. Journal of Infection, 2013, 68, pp.S125-S133. 10.1016/j.jinf.2013.09.023 . hal-00875492

\section{HAL Id: hal-00875492 \\ https://hal.science/hal-00875492}

Submitted on 6 Dec 2013

HAL is a multi-disciplinary open access archive for the deposit and dissemination of scientific research documents, whether they are published or not. The documents may come from teaching and research institutions in France or abroad, or from public or private research centers.
L'archive ouverte pluridisciplinaire HAL, est destinée au dépôt et à la diffusion de documents scientifiques de niveau recherche, publiés ou non, émanant des établissements d'enseignement et de recherche français ou étrangers, des laboratoires publics ou privés. 


\title{
It is not only the cat that did it: how to prevent and treat congenital toxoplasmosis
}

\section{Florence Robert-Gangneux}

Keywords : Congenital toxoplasmosis, pregnancy, treatment, prevention, epidemiology

Copyright statement: a few sentences in paragraphs $\S 2.2$, and 2.3 were drawn from a previous manuscript, "Copyright (C) American Society for Microbiology [Clin Microbiol Rev. 2012 Apr;25(2):264-96. doi: 10.1128/CMR.05013-11] “, in accordance with CMR copyright policy.

\begin{abstract}
The apicomplexan parasite Toxoplasma gondii was discovered a little over one hundred years ago and was soon recognized as a pathogen responsible for congenital infection. But detailed understanding of its epidemiology emerged only after 1970 with the discovery of its life cycle. In the last ten years, high resolution molecular tools have allowed the characterisation of various strain types with different virulence patterns, and current studies are exploring the distribution of these different genotypes. In parallel, sophisticated diagnostic tools have been developed and awareness of disease burden has led some European countries with high prevalence rates to implement screening of pregnant women. In this article, the screening
\end{abstract}


options and therapies used to prevent congenital toxoplasmosis are dissected in the light of recent data from cohort studies and other epidemiological data.

\section{Introduction}

Infection with the protozoan Toxoplasma gondii is one of the most frequent parasitic infections worldwide. This obligate intracellular parasite was first described in the gondi, a rodent from North Africa, by Nicolle and Manceaux in 1908 [1], and was subsequently recognized as the agent of a widespread zoonosis involving humans as well as virtually all warm-blooded animals and birds. However, it was several decades before its entire life cycle was eludicated in the late 1960s [2-4], with the demonstration of the cat as the definitive host responsible for oocyst shedding through feces and contamination of intermediate hosts.

Significant steps towards understanding and control of human infection include the first reports of cases of congenital toxoplasmosis in 1939 [5], the development of the first serologic test by Sabin \& Feldman in 1948, the recognition, in the mid-1970s, that past infection could reactivate in immunocompromised patients [6] and the development of prevention policies in some European countries to reduce the burden of congenital toxoplasmosis. During the last decade, the development of new genotyping tools and the multiplication of field studies have increased comprehension of the phylogenetic evolution of T. gondii globally [7] and of virulence associated with some specific genotypes [8].

This article aims to provide an update on the epidemiology of toxoplasmosis and to summarise approaches to management of toxoplasmosis during pregnancy and childhood. 


\section{New insights into the epidemiology of toxoplasmosis}

\subsection{Life cycle of Toxoplasma gondii and sources for human infection}

There are three infective stages of $T$. gondii, of which the first two are found in intermediate hosts including humans: i) the rapidly dividing tachyzoite stage, the disseminating form which is capable of invading all nucleated cells and thus all organs, ii) the quiescent bradyzoite form, present typically in hundreds within tissue cysts, which can persist lifelong after infection, mostly in muscles, retina and brain, and iii) the sporozoite-containing oocyst, generated after sexual replication in the intestinal tract of the definitive hosts, i.e. cats and other Felidae, and massively contaminating the environment (Figure 1). More details can be found in recent reviews [9-10]. Oocysts are responsible for direct infection of humans and herbivores/rodents/birds, usually through contamination of food and pastures / soil, respectively. Secondarily, mammals and birds are themselves a potential source of contamination for carnivores through ingestion of cyst-containing tissues, and the parasite can propagate in wildlife through a dynamic involving carnivore-to-carnivore or herbivoreto-carnivore transmission.

All 3 stages are susceptible to heating above $65^{\circ} \mathrm{C}$ and thus are killed by cooking (cystcontaining meat, vegetables contaminated with oocysts), or pasteurization (milk contaminated with tachyzoites). However, they are differently affected by freezing. Indeed, whereas cysts are usually killed by freezing at $-20^{\circ} \mathrm{C}$ for at least 15 days [11-12], oocysts can survive at -10 to $-20^{\circ} \mathrm{C}$ for several months [13-14].

Consequently, humans can become infected in various ways. Oral contamination can occur through direct ingestion of oocysts after consumption of raw vegetables or contaminated 
water, or through dirty hands after gardening, outdoor recreation activities or cat contact. Secondly, the widespread distribution of the parasite in animals, as intermediate hosts supporting asexual replicating stages, offers a wide range of opportunities for human infection through ingestion of undercooked meat (Figure 1). Another way of acquiring Toxoplasma infection through cysts is by transplantation of an organ from an infected donor to an uninfected recipient. Finally, vertical transmission can follow maternal primary infection during pregnancy, by transplacental transfer of tachyzoites during blood stream dissemination.

\subsection{Prevalence of toxoplasmosis}

\subsubsection{Prevalence in animals}

Toxoplasma infection has been described in more than 350 host species, mammals and birds, the vast majority of them living in a wild environment [15]. Prevalence in these intermediate hosts depends on the presence of felids in their environment. The processes promoting infection in animal populations are highly complex and involve the interaction of various characteristics: i) climate, as areas with dry and hot climates are unfavourable to oocyst survival and are associated with lower prevalence in wild animals, while higher prevalence is observed in humid tropical countries [13], ii) the susceptibility of the host species to Toxoplasma infection, and iii) the host species' diet and feeding behaviour [9].

Prevalence among animals bred for meat-production varies according to the geographical area, but also to the type of breeding. Rates of Toxoplasma infection in livestock have been considerably reduced in areas with intensive farm management, adequate hygiene and confinement avoiding the presence of rodents, birds, and cats, and feeding meat-producing 
animals on sterilized food [16]. Thus, seroprevalence in slaughter pigs is now $<5 \%$ in most industrialized countries [17]. Prevalence in meat producing animals kept on pasture, such as sheep, goats and horses remains unchanged. Actually, sheep, rather than pigs, are the main source of infected meat in southern European countries, with a prevalence increasing from $17-22 \%$ in lambs to $65-89 \%$ in adult [18]. Seropositivity reported in goats varies from $4-77 \%$ [15], while it is generally lower in horses [19].

\subsubsection{Prevalence in humans}

Estimates indicate that approximately 25 to $30 \%$ of the world human population is infected by Toxoplasma [20]. The prevalence varies widely between countries (from 10 to $80 \%$ ) and often within a given country and even between different communities living in a same region [21]. Low seroprevalence (10-30\%) is observed in North America, in South East Asia, in Northern Europe, and in Saharan countries of Africa. Moderate prevalence (30-50\%) is found in countries of central and southern Europe, and high prevalence in South America and in tropical African countries. As in animals, many factors can affect seroprevalence in humans. Climatic factors affecting survival of oocysts in the environment, and hence infection of meat-producing animals, are naturally important. But many other factors may explain large variations in human seroprevalence, such as cooking habits, socio-economic levels, social or cultural habits, quality of water and sanitation coverage. Seroprevalence has declined over recent decades in most industrialized countries, probably as a result of multiple factors including improved socioeconomic levels, improvements in hygiene, changes in farming systems, consumption of frozen meat, and feeding of cats with sterilized food. For example, in France, the seroprevalence in pregnant women was about $80 \%$ in the early sixties, and declined to 54\% and 44\% in two national surveys in 1995 and 2003, respectively, while at the 
same time the average age of first pregnancy increased [22]. From the 2003 national survey, the mean infection rate during pregnancy was estimated to be 6-7 per 1000 seronegative pregnant women [23]. The incidence at birth was about 3 per 10,000 live births in 2007 in France [22], which is in the same range as incidence rates reported in other European countries, such as Denmark (2.1/10,000 live births) and Switzerland (4.3/10,000 live births), but is higher than that reported in Sweden $(0.73 / 10,000)$ and in a pilot study in Massachussetts $(1 / 10,000)$ [24] and lower than in Brazil $(6 / 10,000)$ [25].

\section{3 Genotype distribution and virulence: implications for human disease}

Although one single parasite species is responsible for toxoplasmosis in humans and animals, it has been shown that from the 1990s, clinical isolates from Europe and USA could be divided into three major genotypes: types I, II and III, equivalent to clonal lineages, stable in time and space [26-28]. However, multilocus and multi-chromosome genotyping of isolates from other continents revealed a much more complex population structure with a greater genetic diversity likely reflecting frequent exchanges between hosts and recombination of isolates during the sexual life cycle within the definitive hosts [29]. This led to the generation of recombinant isolates (I/II, I/III or II/III), but also to new clonal haplogroups (12 are now described in the world including the three initial types I, II, III), and in some areas, particularly in South America, to atypical genotypes with many unique polymorphisms which cannot be clustered into one of these haplogroups. In Europe, type II strains markedly predominate both among humans and animals [30-31], and are isolated in more than $90 \%$ of congenital infections in France. Other clonal lineages are occasionally (type III) or exceptionally (type I) described in Europe. The exceptional isolation of atypical strains in France can be related to travels in South America or consumption of imported meat [32]. The 
epidemiological picture is relatively similar in North America, where type II strains also predominate [27], but recent data suggest a higher prevalence of atypical strains in North America and another clonal haplogroup (haplogroup 12) has recently been identified [33]. By contrast, atypical genotypes largely predominate in South America, whereas type II isolates are very rare. [34]. In Africa, clonal lineages known as Africa 1-3 haplogroups coexist with type II and III lineages [35]. Data from Asia are scarce, but some studies reveal a more limited genetic diversity than in South America, with the widespread presence of a clonal lineage in China [36].

It has long been thought that the immune background of the patient, as well as the trimester of pregnancy at maternal infection, were the key explanatory factors for the severity of clinical signs in adults and in the foetus, respectively. In the light of recent knowledge of genotype strains, this interpretation needs to be somewhat modified. The fact that infection is usually asymptomatic when it occurs in an immunocompetent subject is not questioned in Europe and North America, but recent experience from French Guyana using new genotyping tools, shows that severe and even lethal toxoplasmosis can be observed in immunocompetent patients infected with atypical strains [37]. Similar observations have been made in Brazil, where cases of retinochoroiditis, including clusters [38], have been repeatedly described in the context of primary toxoplasmosis [39], an event which has now also been described in Europe, but to a far lesser extent [40]. The pathophysiology of acquired toxoplasmosis during pregnancy should be also revised. The common notion is that the frequency of transplacental transmission increases with the age of gestation. That the degree of foetal damage is dependent on gestational age at maternal infection cannot not denied, but recent observations have also shown that: i) re-infection with an atypical strain of a previously infected woman can result in congenital transmission [41], and ii) the rate of severe congenital infection is 
higher when women were infected with an atypical or recombinant strain than with a type II strain. Indeed, cumulative data (2006-2011) from the French national network of the Centre National de Référence de la Toxoplasmose show that about $92 \%$ of congenital infections are due to Type II strains, of which $84 \%$ are asymptomatic infections, whereas $83 \%$ of infections with atypical or recombinant genotypes are symptomatic (https://www. chureims.fr/professionnels/cnr-toxoplasmose-1).

\section{Prevention of toxoplasmosis during pregnancy}

\subsection{Actualization of primary prevention measures}

Prevention of congenital infection relies primarily on hygienic measures to avoid infection. Targeted counselling could be directed towards seronegative women, if serologic screening is routine. A written document spelling out the various recommendations should be given and explained for better compliance. Prevention messages include hygienic measures related to cats, the importance of cooking meat well and washing vegetables to be eaten raw thoroughly, as well as of hand washing (Table 1). Drinking water has recently emerged as a new risk factor in some countries including Brazil, India and Canada [42-44], depending on the source of the water supply network (surface or ground water) and on the sanitary level or the use of well water. In addition, an American study describes possible infection from ingestion of water during outdoor recreational activities [45], a widespread hobby in North America, which could partly explain high rates of infections of unknown origin [46]. Therefore, the consumption of mineral or sterilized water could be recommended for pregnant women, as well as care with regard to water-based activities in lakes or rivers. In view of recent information about virulent strains, it is likely that these hygienic measures 
could be also beneficial for seropositive pregnant women who travel in South America or in Africa.

\subsection{Serologic screening}

Serologic screening is another part of primary prevention, which focuses on the foetus. Indeed, it is based on the early detection of infection in the mother to allow early treatment aiming to reduce vertical transmission, and any foetal sequelae.

Such screening has been performed in France for 20 years and involves initial serology during the first trimester of pregnancy followed by monthly testing in seronegative women.

Other countries also have screening policies (Austria, Belgium, Italy, Lithuania, Slovenia)[47], but the frequency of follow up serologic testing varies from one to three monthly. Some countries do not recommend screening (United Kingdom, Norway, Finland), arguing either that seroprevalence is too low for cost effectiveness, or that maternal stress in the case of diagnosis by detecting seroconversion or that foetal risk associated with amniocentesis are unacceptable. Other countries have no specific recommendations concerning prenatal screening [48].

4 Reducing the burden of congenital toxoplasmosis

\subsection{Prenatal treatment}

\subsubsection{Treatment schemes and management of pregnancy surveillance}


Serologic screening offers the opportunity to treat the mother as soon as the primary infection is detected, and to propose prenatal diagnosis, the negative predictive value of which is at least 90\% [49-50] when using sensitive PCR targets, thus allowing reassurance of the couple if parasitologic detection in amniotic fluid is negative. On the other hand, when foetal infection is diagnosed, it prompts changing standard spiramycin treatment (3 MIU/tid) to a pyrimethamine-sulphadiazine combination which is considered to be more effective in reducing foetal sequelae. Regular monthly follow-up ultra-sound scans are also usually scheduled throughout the rest of the pregnancy.

\subsubsection{Does prenatal treatment reduce vertical transmission?}

The question of treatment efficacy is contentious. Several multicentre studies and metaanalyses have yielded contradictory and possibly biased results. One problem is the frequent absence of an untreated control group of approximately the same size as the treated group in clinical practice. Participating centres which include patients in studies and case series are generally engaged in the diagnosis of congenital toxoplasmosis and usually prescribe antenatal treatment to mothers. Where local clinical equipoise is absent, an untreated control group is difficult to justify ethically. Assembling control group data from patients from countries where prenatal screening and treatment is not implemented, but where infected newborns are diagnosed through postnatal screening results in important gaps in the data such as the age of gestation at maternal infection, which is a determinant of transmission as well as severity of foetal injury and needs to be comparable between groups. Among treated patients, the dating of maternal infection can usually be achieved more or less precisely by retrospective analysis of stored sera taken during pregnancy. Last but not least, studies must take into account the delay to treatment after maternal infection. This also depends on the 
frequency of serologic screening. Monthly screening as performed in France results in rapid implementation of treatment, whereas 3-monthly testing may result in delays and potentially reduced efficacy.

The consequential difficulties are evident in the attempts made to date to synthesise the evidence. The first meta-analysis in the field [51] included 9 papers and did not find any effect of treatment in reducing vertical transmission, but with important limitations as discussed, namely: i) the lack of an untreated control group, ii) the lack of sufficiently long follow-up of newborns to rule out congenital infection with a high degree of confidence, and iii) uncertainty concerning the delay between maternal infection and onset of treatment. Similar conclusions were drawn from a European multicentre study [52] which included 1,208 mothers of whom only 106 were untreated controls $(<10 \%)$. The authors acknowledged a lack of power and the weakness that data were heterogeneous (differences between treatment regimens and variable initiation delays depending on serological screening policies. Indeed, these were compounded as the median delay for treatment with spiramycin was about 4 weeks, whereas it was $>8$ weeks with the potentially more effective pyrimethamine sulphadiazine regimen).

In 2007, a larger systematic review (SYROCOT study) included 26 cohorts from USA and Europe, reporting 1,745 mothers, of whom 307 were not treated (18\%), and 691 infected newborns [53]. The authors concluded that transmission was reduced if treatment was started less than 3 weeks after infection, when compared to a delay of greater than 8 weeks $(p<0.05)$, but found no difference between treatment spiramycin and pyrimethamine - sulphadiazine treatment regimens.

Finally, a recent French study addressed indirectly the efficiency of prenatal management on the burden of disease, by analysing the impact of the implementation of screening policy. 
The authors found that the transmission rate was higher in the period 1987-1991, i.e. before the implementation of mandatory monthly serologic screening, than in the period 1992-2008 [54].

\subsubsection{Does prenatal treatment reduce foetal sequelae?}

To address this question, the SYROCOT study [53] included 1,438 mothers and 550 infected newborns from Europe to avoid possible bias due to more virulent strains circulating in America. One hundred and five infants (19\%) had clinical manifestations (14\% with ocular lesions, 9\% with intracranial lesions). The odds of cerebral manifestations decreased as expected with the age of gestation, but although the odds ratio appeared lower with treatment, the $95 \%$ confidence limits crossed 1 and no clear effect of type and timing of treatment was observed. As there were missing data in $15 \%$, this adds further uncertainty regarding outcome. What this study gains in size and thus power it loses through heterogeneity of data.

For several other studies which yielded concordant conclusions as to the efficacy of prenatal treatment in reducing cerebral sequelae, it tends to be the other way around. In a prospective study, Gras et al. [55] followed 255 live-born infected infants and observed that any prenatal treatment within 4 weeks of seroconversion was associated with reduced risk of intracranial lesions. Another recent European survey [56] including 293 infected foetuses (189 treated, 284 born alive) from 14 centres with 4 years median follow-up, found that any treatment was associated with reduced risk of serious neurological sequelae or death (SNSD). There was no apparent difference in outcome comparing spiramycin with pyrimethamine - sulphadiazine, but again the median interval to starting spiramycin was about 4 weeks, whereas for pyrimethamine - sulphadiazine it was greater than 8 weeks. Point estimates for risk of SNSD 
in this study following seroconversion at 10 weeks of gestation, were $25.7 \%$ and $60 \%$ when mothers were treated or untreated, respectively. An association between early treatment (less than 4 weeks after maternal infection) and reduced foetal damage or sequelae has also been reported in smaller studies [57-58].

The question of the most appropriate treatment is still a matter of debate, since no study showed a clear-cut difference between spiramycin and pyrimethamine-sulfonamide treatment. However, in the recent study of Wallon et al. [54], it appears that a change in the treatment guidelines, i.e. alternating spiramycin and pyrimethamine - sulphadiazine for 3week periods switched to continuous pyrimethamine - sulphadiazine, led to a highly significant reduction of clinical signs in infected children.

The impact of prenatal treatment on ocular sequelae is less clear and more difficult to evaluate. Eye lesions can develop years after birth, whether children have been treated antenatally or not. What may differ is the frequency of recurrence of episodes or the severity of the lesions. Although several studies showed no effect of prenatal treatment on eye sequelae [53, 55], Kieffer et al. [59] reported that the incidence of ocular lesions below 2 years of age was associated with maternal treatment delayed to more than 8 weeks after infection and with the presence of intracerebral calcifications at birth.

It is of interest to note that the incidence of symptomatic congenital toxoplasmosis in France was estimated to be 0.34 cases per 10,000 live births (about $11 \%$ of infected neonates) in 2007 and subsequently whereas, despite much lower seroprevalence in England (about 10\% compared to $44 \%$ in France), the equivalent incidence rate has been estimated to be rather similar (0.16 per 10,000 live births).[60] Although there may be differences in ascertainment or other biasing factors to account for this, it might also reflect the impact of systematic screening and treatment of women with acquired toxoplasmosis during pregnancy in France which is not done in England. 
A recent US study addressed the societal cost of congenital toxoplasmosis using a decisionanalytic economic model and evaluating a prenatal screening system similar to that implemented in France (maternal serologic screening, prenatal diagnosis and treatment) and concluded that, even in a country like the USA with a very low infection rate of 1 per 10,000 live births, universal prenatal screening would be cost-saving [61]. This study estimated the costs of mild visual loss and of severe toxoplasmosis to be 500,000 US\$ and 2.7 million US\$, respectively.

\subsection{Postnatal treatment}

\subsubsection{Treatment regimens}

Treatment of congenitally infected children consists of a combination of pyrimethamine and a sulphonamide (sulphadiazine or sulphadoxine). Two treatment regimens are widely used, sometimes with minor modifications in dose or length (Table 2). In case of severe abnormalities at birth, including neurological signs and/or $>1$ ocular lesions and/or $>3$ intracerebral calcifications, the higher dose longer regimen is recommended (Table 2). Since these treatments can have bone marrow toxicity, regular blood counts should be performed, at least twice monthly. Neutropenia is more frequently observed in patients treated with pyrimethamine-sulphadiazine [62], sometimes leading to interruption of therapy for about 2 to 3 weeks until neutrophil counts recover above $1,000 / \mathrm{mL}$.

\subsubsection{Does postnatal treatment reduce the frequency and severity of clinical manifestations during childhood?}


Ideal studies to answer this question are also difficult to conduct. Not only would infected infants need to be identified in a timely fashion perhaps by postnatal screening but they would also have to be randomised to treatment or placebo which, in the absence of clinical equipoise is once again ethically unacceptable. In addition, the effectiveness of postnatal treatment could be affected by whether antenatal treatment had been used. In practice, the best that can be done is to draw information from retrospective cohort studies. These provide two distinct pictures of disease, one from Northern America and the other from Europe.

\subsubsection{The US cohorts}

In Northern America, where no prenatal screening is implemented, most cases are diagnosed on the basis of clinical signs which lead to referral to a specialist centre. Asymptomatic cases remain for the most part undetected and resulting in a probable overestimation of typical disease severity, except in centres or states (Massachussetts, New Hampshire, New England, Chicago IL) where local postnatal screening schemes were implemented in the 1990s.

In spite of this partial epidemiological view, large longitudinal studies performed in these centres with the participation of the Reference Centre Toxoplasma Serology Laboratory (Palo Alto, CA, USA) have provided a consistent body of data comparing clinical outcomes of children treated in early infancy and untreated infants from historical series. What emerged from these cohort studies is that better neurologic and developmental outcomes were observed in children who were treated for one year than in untreated children [24, 63-65], notably in terms of neurological signs, seizures, IQ, vision, or occurrence of new eye lesions. In older series, untreated infants, though asymptomatic at birth, developed high rates of ocular lesions $(92 \%)$ or neurologic sequelae (12\%) [66], or suffered from recurrent episodes 
of retinochoroiditis $(72 \%)$, despite spot treatment at time of diagnosis and at each recurrent lesion [67]. Compared to this poor outcome, a striking improvement was observed in cohorts benefiting from local postnatal screening policy and treatment, as, for example, the New England initiative, who reported that only $10 \%$ of infants treated for one year after birth, developed recurrent retinal lesions.

Together, these findings suggest that postnatal treatment greatly improves the clinical outcome in children who did not receive prenatal treatment, supporting the case for screening at birth to diagnose infected infants. However, recent observations concerning the epidemiology of parasite strains in North America suggest that the high disease burden there could be due not only to the absence of prenatal management or postnatal treatment, but also to the circulation of type non-II strains, which may be more virulent [68].

\subsubsection{The European cohorts}

In most European studies, a large proportion of cases received prenatal treatment, thus the respective effects of prenatal and postnatal treatments are hard to distinguish. Several large series report a low rate of clinical symptoms at birth. Of 325 infants treated for 1 year, Wallon et al. [69] reported only 3\% of ocular lesions at birth and $69 \%$ of them had normal visual acuity at age 6. Similar results were observed in another French study, with $8.7 \%$ having eye lesions at birth and about 10\% during a mean follow-up of 4 years [70]. An interesting point in terms of prognosis was the observation that symptomatic children developed eye lesions at a young age, as $75 \%$ and $92 \%$ of them had retinochoroiditis at age $<2$ and at age $<5$, respectively, indicating that late occurrence of eye lesion is scarce in treated children. In a multicentre study including infants from France, Austria, Italy, Poland, 
and Scandinavia, the authors reported an $18 \%$ rate of ocular disease [71]. The risk of eye lesions by the age of 4 years was higher in children with neurologic sequelae, intracerebral calcifications or hepatosplenomegaly, an association previously reported by Kieffer et al. [59]. In contrast, children with no sign of retinochoroiditis at 4 months of age had a low risk of developing eye lesions by the age of 4 years [71]. Therefore, it has been proposed that children with no clinical signs at birth and normal foetal ultrasound, i.e. about $80 \%$ of live born infected infants in Europe, could be offered short course treatment ( 3 months) instead of 1 year [71], with yearly fundus examinations. Conversely, children with ocular lesions at birth or otherwise at high risk for developing retinochoroiditis, i.e. with foetal ultrasound abnormalities or neurologic impairment, should receive full course treatment along with repeated ocular examination [72]. However, it must be underlined that these adapted recommendations should be validated in a randomized clinical trial. While they may be pertinent in Europe where low virulence Type II strains largely predominate, they cannot be applied to the American continent, particularly South America. A national clinical trial is underway in France to evaluate the equivalence of 3-month and 12-month treatment in asymptomatic infected neonates.

\subsection{Concluding remarks and synthesis for clinical practise}

The disease burden of congenital toxoplasmosis has probably decreased in European countries where prevalence was high, thanks to the implementation of prevention policies. Today, some studies are examining the usefulness of screening and prolonged follow-up. The efficacy of prevention combined with the predominance of low virulent strains may have minimized disease burden in Europe as compared to South America, but one should take care not to underestimate the benefits of integrated management of toxoplasmosis. Shorter 
postnatal treatment schemes could be proposed in the future, at least for asymptomatic newborns.

\section{Conclusion}

Great advances have been achieved in the fields of diagnosis and epidemiology of toxoplasmosis. It appears now that clinical aspects of toxoplasmosis must be unravelled in the light of Toxoplasma genotypes and of their geographical distribution. Primary prevention measures now need to take the risks associated with water consumption and travel into consideration. Prenatal screening has been challenged after studies questioning the efficacy of prenatal treatment, but more recent articles suggest that treatment reduces severe sequelae at birth. The impact of such screening policies varies with the seroprevalence which is very different among countries, thus the cost-benefit ratio must always be carefully evaluated. In countries where postnatal screening has been implemented, symptomatic children should be treated to prevent aggravation of symptoms and neurologic deterioration. The use of full or abbreviated treatment regimens for asymptomatic infected children is currently under debate in Europe, but ongoing studies should resolve this issue.

\section{Conflict of interest: none to disclose.}




\section{References}

[1] Nicolle C, and L. Manceaux. Sur une infection à corps de Leishman (ou organismes voisins) du gondi. CR Hebd Séances Acad Sci. 1908;147:763-6.

[2] Dubey JP, Frenkel JK. Cyst-induced toxoplasmosis in cats. J Protozool. 1972;19:155-77.

[3] Hutchison WM, Dunachie JF, Siim JC, Work K. Life cycle of toxoplasma gondii. Br Med J. 1969;4:806.

[4] Frenkel JK, Dubey JP, Miller NL. Toxoplasma gondii in cats: fecal stages identified as coccidian oocysts. Science. 1970;167:893-6.

[5] Schwartzman J, Maffia A, et al. Congenital toxoplasmosis. J Pediatr. 1948;33:66-73.

[6] Weiss LM, Dubey JP. Toxoplasmosis: A history of clinical observations. Int J Parasitol. 2009;39:895-901.

[7] Mercier A, Ajzenberg D, Devillard S, Demar MP, de Thoisy B, Bonnabau H, et al. Human impact on genetic diversity of Toxoplasma gondii: Example of the anthropized environment from French Guiana. Infect Genet Evol. 2011.

[8] ElHajj H, Lebrun M, Arold ST, Vial H, Labesse G, Dubremetz JF. ROP18 is a rhoptry kinase controlling the intracellular proliferation of Toxoplasma gondii. PLoS Pathog. 2007;3:e14.

[9] Robert-Gangneux F, Darde ML. Epidemiology of and diagnostic strategies for toxoplasmosis. Clin Microbiol Rev. 2012;25:264-96.

[10] Dubey JP. Advances in the life cycle of Toxoplasma gondii. Int $\mathbf{J}$ Parasitol. 1998;28:1019-24.

[11] Lunden A, Uggla A. Infectivity of Toxoplasma gondii in mutton following curing, smoking, freezing or microwave cooking. Int J Food Microbiol. 1992;15:357-63. 
[12] Dubey JP. Long-term persistence of Toxoplasma gondii in tissues of pigs inoculated with $\mathrm{T}$ gondii oocysts and effect of freezing on viability of tissue cysts in pork. Am $\mathrm{J}$ Vet Res. 1988;49:910-3.

[13] Dubey JP. Toxoplasma gondii oocyst survival under defined temperatures. J Parasitol. $1998 ; 84: 862-5$.

[14] Frenkel JK, Dubey JP. Effects of freezing on the viability of toxoplasma oocysts. J Parasitol. 1973;59:587-8.

[15] Tenter AM, Heckeroth AR, Weiss LM. Toxoplasma gondii: from animals to humans. Int J Parasitol. 2000;30:1217-58.

[16] Kijlstra A, Jongert E. Toxoplasma-safe meat: close to reality? Trends Parasitol. $2009 ; 25: 18-22$.

[17] Dubey JP, Jones JL. Toxoplasma gondii infection in humans and animals in the United States. Int J Parasitol. 2008;38:1257-78.

[18] Halos L, Thebault A, Aubert D, Thomas M, Perret C, Geers R, et al. An innovative survey underlining the significant level of contamination by Toxoplasma gondii of ovine meat consumed in France. Int J Parasitol. 2010;40:193-200.

[19] Dubey JP. Toxoplasmosis of Animals and Humans, . 2nd ed., ed: Boca Raton, F.L.; 2010.

[20] Montoya JG, Liesenfeld O. Toxoplasmosis. Lancet. 2004;363:1965-76.

[21] Pappas G, Roussos N, Falagas ME. Toxoplasmosis snapshots: global status of Toxoplasma gondii seroprevalence and implications for pregnancy and congenital toxoplasmosis. Int J Parasitol. 2009;39:1385-94.

[22] Villena I, Ancelle T, Delmas C, Garcia P, Brezin AP, Thulliez P, et al. Congenital toxoplasmosis in France in 2007: first results from a national surveillance system. Euro Surveill. 2010;15. 
[23] Berger F GV, Le Strat Y, Desenclos JC. Toxoplasmosis in pregnant women in France: trends in seroprevalence and incidence, and associated factors, 1995-2003. Bull Epidemiol Hebd. 2008;14-15:117-21.

[24] Guerina NG, Hsu HW, Meissner HC, Maguire JH, Lynfield R, Stechenberg B, et al. Neonatal serologic screening and early treatment for congenital Toxoplasma gondii infection. The New England Regional Toxoplasma Working Group. N Engl J Med. 1994;330:1858-63. [25] Lago EG, Neto EC, Melamed J, Rucks AP, Presotto C, Coelho JC, et al. Congenital toxoplasmosis: late pregnancy infections detected by neonatal screening and maternal serological testing at delivery. Paediatr Perinat Epidemiol. 2007;21:525-31.

[26] Darde ML, Bouteille B, Pestre-Alexandre M. Isoenzyme analysis of 35 Toxoplasma gondii isolates and the biological and epidemiological implications. J Parasitol. 1992;78:78694.

[27] Howe DK, Sibley LD. Toxoplasma gondii comprises three clonal lineages: correlation of parasite genotype with human disease. J Infect Dis. 1995;172:1561-6.

[28] Ajzenberg D, Banuls AL, Tibayrenc M, Dardé ML. Microsatellite analysis of Toxoplasma gondii shows considerable polymorphism structured into two main clonal groups. Int J Parasitol. 2002;32:27-38.

[29] Ajzenberg D, Banuls AL, Su C, Dumetre A, Demar M, Carme B, et al. Genetic diversity, clonality and sexuality in Toxoplasma gondii. Int J Parasitol. 2004;34:1185-96.

[30] Ajzenberg D, Cogne N, Paris L, Bessieres MH, Thulliez P, Filisetti D, et al. Genotype of 86 Toxoplasma gondii isolates associated with human congenital toxoplasmosis, and correlation with clinical findings. J Infect Dis. 2002;186:684-9.

[31] Aubert D, Ajzenberg D, Richomme C, Gilot-Fromont E, Terrier ME, de Gevigney C, et al. Molecular and biological characteristics of Toxoplasma gondii isolates from wildlife in France. Vet Parasitol. 2010;171:346-9. 
[32] Pomares C, Ajzenberg D, Bornard L, Bernardin G, Hasseine L, Darde ML, et al. Toxoplasmosis and horse meat, france. Emerg Infect Dis. 2011;17:1327-8.

[33] Khan A, Dubey JP, Su C, Ajioka JW, Rosenthal BM, Sibley LD. Genetic analyses of atypical Toxoplasma gondii strains reveal a fourth clonal lineage in North America. Int $\mathbf{J}$ Parasitol. 2011;41:645-55.

[34] Pena HF, Gennari SM, Dubey JP, Su C. Population structure and mouse-virulence of Toxoplasma gondii in Brazil. Int J Parasitol. 2008;38:561-9.

[35] Mercier A, Devillard S, Ngoubangoye B, Bonnabau H, Banuls AL, Durand P, et al. Additional haplogroups of Toxoplasma gondii out of Africa: population structure and mousevirulence of strains from Gabon. PLoS Negl Trop Dis. 2010;4:e876.

[36] Zhou P, Nie H, Zhang LX, Wang HY, Yin CC, Su C, et al. Genetic characterization of Toxoplasma gondii isolates from pigs in China. J Parasitol. 2010;96:1027-9.

[37] Carme B, Bissuel F, Ajzenberg D, Bouyne R, Aznar C, Demar M, et al. Severe acquired toxoplasmosis in immunocompetent adult patients in French Guiana. J Clin Microbiol. 2002;40:4037-44.

[38] Silveira C, Belfort R, Jr., Burnier M, Jr., Nussenblatt R. Acquired toxoplasmic infection as the cause of toxoplasmic retinochoroiditis in families. Am J Ophthalmol. 1988;106:362-4.

[39] Silva CS, Neves Ede S, Benchimol EI, Moraes DR. Postnatal acquired toxoplasmosis patients in an infectious diseases reference center. Braz J Infect Dis. 2008;12:438-41.

[40] Delair E, Monnet D, Grabar S, Dupouy-Camet J, Yera H, Brezin AP. Respective roles of acquired and congenital infections in presumed ocular toxoplasmosis. Am J Ophthalmol. 2008;146:851-5.

[41] Elbez-Rubinstein A, Ajzenberg D, Darde ML, Cohen R, Dumetre A, Yera H, et al. Congenital toxoplasmosis and reinfection during pregnancy: case report, strain 
characterization, experimental model of reinfection, and review. J Infect Dis. 2009;199:2805.

[42] Bahia-Oliveira LM, Jones JL, Azevedo-Silva J, Alves CC, Orefice F, Addiss DG. Highly endemic, waterborne toxoplasmosis in north Rio de Janeiro state, Brazil. Emerg Infect Dis. 2003;9:55-62.

[43] Balasundaram MB, Andavar R, Palaniswamy M, Venkatapathy N. Outbreak of acquired ocular toxoplasmosis involving 248 patients. Arch Ophthalmol. 2010;128:28-32.

[44] Bowie WR, King AS, Werker DH, Isaac-Renton JL, Bell A, Eng SB, et al. Outbreak of toxoplasmosis associated with municipal drinking water. The BC Toxoplasma Investigation Team. Lancet. 1997;350:173-7.

[45] Jones JL, Dubey JP. Waterborne toxoplasmosis--recent developments. Exp Parasitol. $2010 ; 124: 10-25$.

[46] Jones JL, Dargelas V, Roberts J, Press C, Remington JS, Montoya JG. Risk factors for Toxoplasma gondii infection in the United States. Clin Infect Dis. 2009;49:878-84.

[47] Benard A, Petersen E, Salamon R, Chene G, Gilbert R, Salmi LR. Survey of European programmes for the epidemiological surveillance of congenital toxoplasmosis. Euro Surveill. $2008 ; 13$.

[48] Leroy V, Pierre-Alain Raeber, PA, Petersen, Salmi L.R, Kaminski, M,, Villena I, Buffolano, W, Gilbert, R, for the Eurotoxo Group (Panel 3). National public health policies and routines programs to prevent congenital Toxoplasmosis, Europe, 2005 [Unpublished report]. Bordeaux (France): The Eurotoxo Group. 2005.

[49] Wallon M, Franck J, Thulliez P, Huissoud C, Peyron F, Garcia-Meric P, et al. Accuracy of real-time polymerase chain reaction for Toxoplasma gondii in amniotic fluid. Obstet Gynecol. 2010;115:727-33.

[50] Centre National de Référence de la Toxoplasmose. 
[51] Wallon M, Liou C, Garner P, Peyron F. Congenital toxoplasmosis: systematic review of evidence of efficacy of treatment in pregnancy. BMJ. 1999;318:1511-4.

[52] Gilbert R, Gras L. Effect of timing and type of treatment on the risk of mother to child transmission of Toxoplasma gondii. BJOG. 2003;110:112-20.

[53] Thiebaut R, Leproust S, Chene G, Gilbert R. Effectiveness of prenatal treatment for congenital toxoplasmosis: a meta-analysis of individual patients' data. Lancet. 2007;369:11522.

[54] Wallon M, Peyron F, Cornu C, Vinault S, Abrahamowicz M, Kopp CB, et al. Congenital toxoplasma infection: monthly prenatal screening decreases transmission rate and improves clinical outcome at age 3 years. Clin Infect Dis. 2013;56:1223-31.

[55] Gras L, Wallon M, Pollak A, Cortina-Borja M, Evengard B, Hayde M, et al. Association between prenatal treatment and clinical manifestations of congenital toxoplasmosis in infancy: a cohort study in 13 European centres. Acta Paediatr. 2005;94:1721-31.

[56] Cortina-Borja M, Tan HK, Wallon M, Paul M, Prusa A, Buffolano W, et al. Prenatal treatment for serious neurological sequelae of congenital toxoplasmosis: an observational prospective cohort study. PLoS Med. 2010;7.

[57] Hotop A, Hlobil H, Gross U. Efficacy of rapid treatment initiation following primary Toxoplasma gondii infection during pregnancy. Clin Infect Dis. 2012;54:1545-52.

[58] Foulon W, Villena I, Stray-Pedersen B, Decoster A, Lappalainen M, Pinon JM, et al. Treatment of toxoplasmosis during pregnancy: a multicenter study of impact on fetal transmission and children's sequelae at age 1 year. Am J Obstet Gynecol. 1999;180:410-5.

[59] Kieffer F, Wallon M, Garcia P, Thulliez P, Peyron F, Franck J. Risk factors for retinochoroiditis during the first 2 years of life in infants with treated congenital toxoplasmosis. Pediatr Infect Dis J. 2008;27:27-32. 
[60] Gilbert R, Tan HK, Cliffe S, Guy E, Stanford M. Symptomatic toxoplasma infection due to congenital and postnatally acquired infection. Arch Dis Child. 2006;91:495-8.

[61] Stillwaggon E, Carrier CS, Sautter M, McLeod R. Maternal serologic screening to prevent congenital toxoplasmosis: a decision-analytic economic model. PLoS Negl Trop Dis. 2011;5:e1333.

[62] McAuley J, Boyer KM, Patel D, Mets M, Swisher C, Roizen N, et al. Early and longitudinal evaluations of treated infants and children and untreated historical patients with congenital toxoplasmosis: the Chicago Collaborative Treatment Trial. Clin Infect Dis. 1994;18:38-72.

[63] Roizen N, Swisher CN, Stein MA, Hopkins J, Boyer KM, Holfels E, et al. Neurologic and developmental outcome in treated congenital toxoplasmosis. Pediatrics. 1995;95:11-20.

[64] McLeod R, Boyer K, Karrison T, Kasza K, Swisher C, Roizen N, et al. Outcome of treatment for congenital toxoplasmosis, 1981-2004: the National Collaborative ChicagoBased, Congenital Toxoplasmosis Study. Clin Infect Dis. 2006;42:1383-94.

[65] Olariu TR, Remington JS, McLeod R, Alam A, Montoya JG. Severe congenital toxoplasmosis in the United States: clinical and serologic findings in untreated infants. Pediatr Infect Dis J. 2011;30:1056-61.

[66] Wilson CB, Remington JS, Stagno S, Reynolds DW. Development of adverse sequelae in children born with subclinical congenital Toxoplasma infection. Pediatrics. 1980;66:76774.

[67] Phan L, Kasza K, Jalbrzikowski J, Noble AG, Latkany P, Kuo A, et al. Longitudinal study of new eye lesions in children with toxoplasmosis who were not treated during the first year of life. Am J Ophthalmol. 2008;146:375-84. 
[68] McLeod R, Boyer KM, Lee D, Mui E, Wroblewski K, Karrison T, et al. Prematurity and severity are associated with Toxoplasma gondii alleles (NCCCTS, 1981-2009). Clin Infect Dis. 2012;54:1595-605.

[69] Wallon M, Kodjikian L, Binquet C, Garweg J, Fleury J, Quantin C, et al. Long-term ocular prognosis in 327 children with congenital toxoplasmosis. Pediatrics. 2004;113:156772.

[70] Faucher B, Garcia-Meric P, Franck J, Minodier P, Francois P, Gonnet S, et al. Longterm ocular outcome in congenital toxoplasmosis: a prospective cohort of treated children. $\mathbf{J}$ Infect. 2012;64:104-9.

[71] Freeman K, Tan HK, Prusa A, Petersen E, Buffolano W, Malm G, et al. Predictors of retinochoroiditis in children with congenital toxoplasmosis: European, prospective cohort study. Pediatrics. 2008;121:e1215-22.

[72] Sauer A, de la Torre A, Gomez-Marin J, Bourcier T, Garweg J, Speeg-Schatz C, et al. Prevention of retinochoroiditis in congenital toxoplasmosis: Europe versus South America. Pediatr Infect Dis J. 2011;30:601-3. 
Figure 1: Sources of human Toxoplasma infection

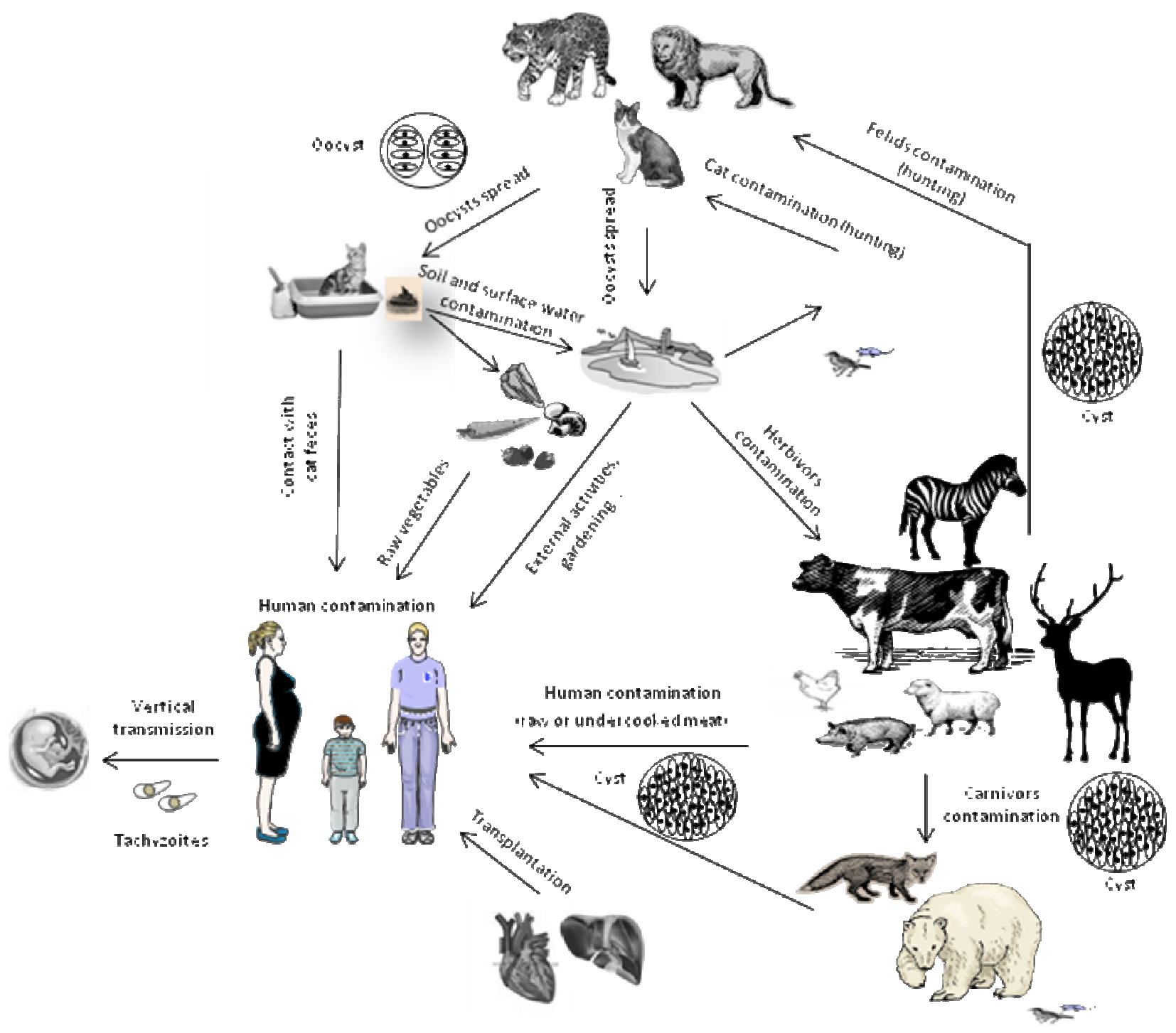




\section{Table captions}

Table 1 Primary measures to prevent Toxoplasma infection

Table 2 Treatment regimens widely used for congenital toxoplasmosis 


\section{Table 1}

\begin{tabular}{|c|c|}
\hline Action or situation & Prevention measures \\
\hline Cat contact & $\begin{array}{l}\text { Wash hands carefully after stroking a cat } \\
\text { Wear gloves when changing the cat litter } \\
\text { Change the litter frequently and wash the tray with } \\
\text { hot water }\left(>60^{\circ} \mathrm{C}\right) \\
\text { Avoid keeping the litter in the kitchen }\end{array}$ \\
\hline Meals & $\begin{array}{l}\text { Cook meat well or stew } \\
\text { Avoid microwave cooking of meat } \\
\text { Avoid raw vegetables at restaurants } \\
\text { Avoid raw shellfish }\end{array}$ \\
\hline Preparation of meals & $\begin{array}{l}\text { Wash vegetables, fruits and herbs eaten raw, } \\
\text { thoroughly especially if they grow close to the ground } \\
\text { Wash hands, knives, any containers and table } \\
\text { thoroughly after raw meat manipulation or cutting }\end{array}$ \\
\hline Water & $\begin{array}{l}\text { Drink bottled or boiled or sterilised rather than } \\
\text { untreated tap water in particular in countries with } \\
\text { surface water supply and in tropical countries }\end{array}$ \\
\hline Gardening \& outdoor activities & $\begin{array}{l}\text { Wash hands thoroughly and brush nails after any } \\
\text { outdoor activities in contact with soil } \\
\text { Wear gloves for gardening } \\
\text { Avoid ingestion of water during recreation activities } \\
\text { in lakes or rivers }\end{array}$ \\
\hline
\end{tabular}


Table 2

\begin{tabular}{|c|c|c|}
\hline Treatment options & $\begin{array}{lll}\text { Asymptomatic } & \text { or mildly } \\
\text { affected child }^{1} & & \end{array}$ & Severely affected child $^{2}$ \\
\hline Pyrimethamine & $\begin{array}{l}1 \mathrm{mg} / \mathrm{kg} / \text { day }(2 \mathrm{months}) \\
\text { then } 0.5 \text { or } 1 \mathrm{mg} / \mathrm{kg} / \text { day }\end{array}$ & $\begin{array}{l}1 \mathrm{mg} / \mathrm{kg} / \text { day }(6 \mathrm{months}) \\
\text { then } 0.5 \text { or } 1 \mathrm{mg} / \mathrm{kg} / \text { day })\end{array}$ \\
\hline and & 3 times/week (10 months) & 3 times/week (6 months) \\
\hline $\begin{array}{l}\text { Sulphadiazine } \\
\text { and } \\
\text { folinic acid }\end{array}$ & $\begin{array}{l}100 \mathrm{mg} / \mathrm{kg} / \text { day (1 year) } \\
50 \mathrm{mg} / \mathrm{wk}\end{array}$ & 100 mg/kg/day (1 year) \\
\hline $\begin{array}{l}\text { Pyrimethamine / } \\
\text { sulphadoxine }(25 / 500 \mathrm{mg}) \\
\left(\text { Fansidar }^{\circledR}\right) \\
\text { and }\end{array}$ & $\begin{array}{l}1 / 4 \text { tab } / 5 \mathrm{~kg} \text { every } 15 \text { days }) \\
(1.25 \mathrm{mg} / \mathrm{kg} \& 25 \mathrm{mg} / \mathrm{kg}) \\
(1-2 \text { years })\end{array}$ & $\begin{array}{l}1 / 4 \text { tab } / 5 \mathrm{~kg} \text { every } 7 \text { days }) \\
(1.25 \mathrm{mg} / \mathrm{kg} \& 25 \mathrm{mg} / \mathrm{kg}) \\
(1-2 \text { years })\end{array}$ \\
\hline folinic acid & $50 \mathrm{mg}$ once/week & $50 \mathrm{mg}$ once/week \\
\hline
\end{tabular}

\footnotetext{
${ }_{1} 1$ ocular lesion and/or $\leq 3$ intracerebral calcifications

${ }^{2}$ neurological signs and/or $>1$ ocular lesion and/or $>3$ intracerebral calcifications
} 